\title{
Analysis and Design of Leaky-Wave Antenna with Low SLL Based on Half-Mode SIW Structure
}

\author{
Jiaying Guo, ${ }^{1,2}$ Zheng Li, ${ }^{1,2}$ Junhong Wang, ${ }^{1,2}$ Meie Chen, ${ }^{1,2}$ and Zhan Zhang ${ }^{1,2}$ \\ ${ }^{1}$ Key Laboratory of All Optical Network and Advanced Telecommunication Network of MOE, Beijing Jiaotong University, \\ Beijing 100044, China \\ ${ }^{2}$ Institute of Lightwave Technology, Beijing Jiaotong University, Beijing 100044, China \\ Correspondence should be addressed to Zheng Li; lizheng@bjtu.edu.cn
}

Received 13 October 2014; Accepted 6 February 2015

Academic Editor: Giuseppe Mazzarella

Copyright (C) 2015 Jiaying Guo et al. This is an open access article distributed under the Creative Commons Attribution License, which permits unrestricted use, distribution, and reproduction in any medium, provided the original work is properly cited.

\begin{abstract}
This paper presents a novel leaky-wave antenna based on the Half-Mode Substrate Integrated Waveguide (HMSIW) structure with low side lobe level. The effect of the structural parameters of the LWAs on the radiation performances is studied. Using beamforming technique, the leakage loss factor $\alpha$ along the radiation aperture is designed in a tapered way by controlling the aperture depth along the structure. This controls the radiated power along the antenna aperture and finally achieves the radiation pattern with low SLL. Furthermore, the antenna structure is optimized to get an even lower SLL.
\end{abstract}

\section{Introduction}

Leaky-wave antennas (LWAs) have been widely used in microwave and millimeter-wave applications for their capability of beam scanning by frequency and high directivity [1-4]. The LWA based on the substrate integrated waveguide (SIW) was recently proposed, which has significant features such as high $Q$ value, high power capacity, low loss, and low cost $[5,6]$. Among different kinds of SIWs, a more compact guided-wave structure called Half-Mode Substrate Integrated Waveguide (HMSIW) was proposed [7-9]. As we know, the magnitude of $E$-field of dominant mode in SIW reaches its maximum in the symmetry plane of SIW, which can be seen as a magnetic wall. Therefore, a SIW can be divided into two parts equally, and each one can be seen as a HMSIW structure. The HMSIW structure preserves almost all of the advantages of SIW whereas its size is approximately reduced by half [10].

The available LWAs based on HMSIW structure have the drawback of high side lobe level (SLL) since the aperture field distribution on the magnetic wall is uniform. However, in some applications of LWAs such as radar and communication systems, low SLL is required. For the long slot rectangular waveguide LWAs, in order to realize a low SLL, a tapering aperture field is achieved by meandering the long slot [11].
For the SIW LWAs, two approaches are proposed in [12] to reduce SLL. One of them is to curve the long slot on the top wall of SIW while keeping the array of via holes unchanged. The other is to curve the arrangement of metal via holes array while keeping the slot straight. The second one can simultaneously achieve low SLL and lower cross-polarization level. However, these approaches are used in ordinary SIW LWAs and have not been extended HMSIW yet.

In this paper, a LWA with low SLL based on HMSIW structure is proposed; by meandering the array of metal via holes, the SLL can be reduced effectively. Section 2 describes the structure of the antenna, and the theory and method for analyzing the antenna is presented, the effects of the aperture depth $W$ on the leakage factor $\alpha$ and propagation constant $\beta$ are studied, the distribution of $\alpha$ along the leakage aperture is given. In Section 3, a novel HMSIW LWA with the property of low SLL is designed based on the control of aperture field distribution. Furthermore, the antenna structure is optimized to achieve better performance and the simulation results are presented. Conclusions are summarized in Section 4.

\section{Theory and Method}

2.1. Configuration and Parameters. Figure 1 shows the structure of the HMSIW LWA considered in this paper. $L_{A}$ is 


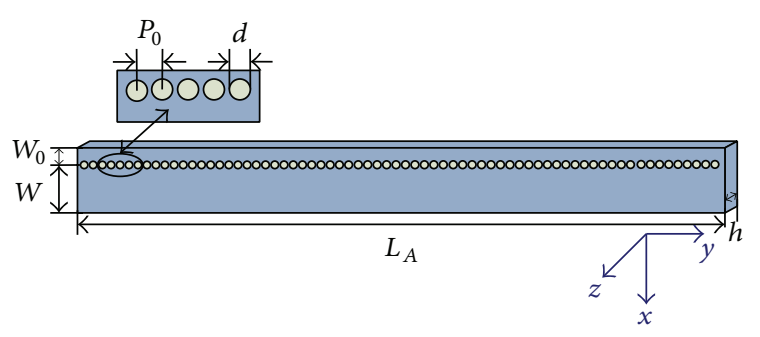

FIgURE 1: Structure of the HMSIW LWA, $L_{A}=136 \mathrm{~mm}, h=$ $1.57 \mathrm{~mm}, W_{0}=1.5 \mathrm{~mm}, P_{0}=2 \mathrm{~mm}$, and $d=1 \mathrm{~mm}$.

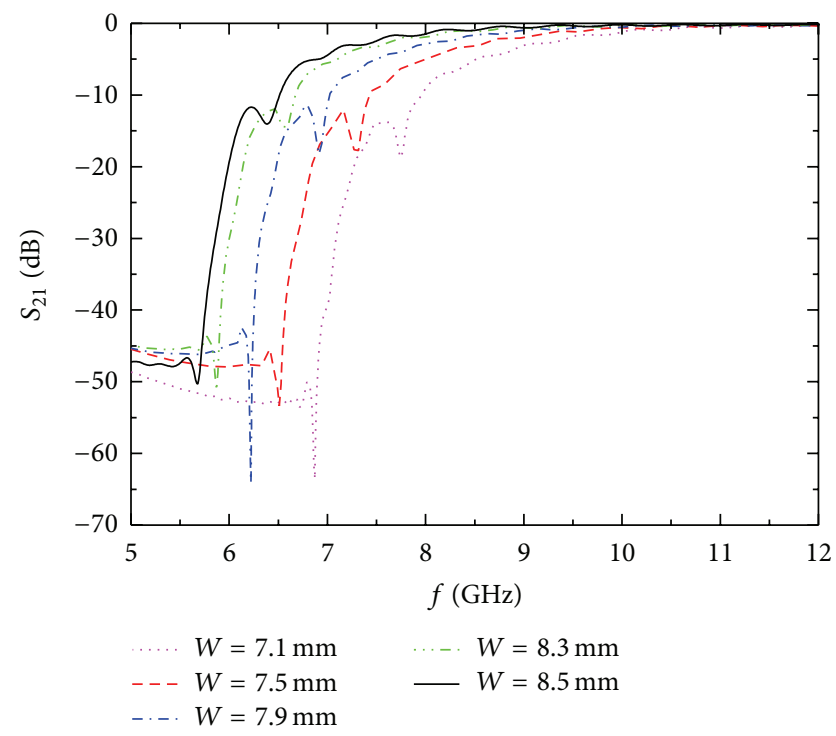

FIGURE 2: Simulated $S_{21}$ of the antenna for different aperture depths.

the antenna length, $h$ is the thickness of substrate and the dielectric constant of substrate is $2.2, W$ is the width between the metal via holes and leakage aperture (also called aperture depth when seen from antenna angle), and $W_{0}$ is the width between the metal via holes and the other edge of waveguide. The via holes of the HMSIW LWA are arranged in $y$-axis with period of $P_{0}$, and the diameter of the via holes is $d$. Usually, the width $W_{0}$ is designed less than $\lambda / 4$ to avoid the undesired channel modes [13-15].

Since the aperture depth $W$ of antenna has significant effect on the cutoff frequency of the HMSIW, it is important to know the range of $W$ within which the structure supports the traveling wave. Figure 2 shows the variation of the $S_{21}$ as function of $W$ and frequency. It can be seen that the cutoff frequency of the waveguide decreases when $W$ increases. In this paper, the operating frequency is set to $8.5 \mathrm{GHz}$, so that the antenna can work within a wide range of $W$ from $7.1 \mathrm{~mm}$ to $8.5 \mathrm{~mm}$.

2.2. Relationship between Leakage Factor and Aperture Depth. For a uniform traveling wave structure, the attenuation constant can be calculated from $S_{21}$ of the structure by [16]

$$
\alpha=-\frac{\log \left|S_{21}\right|}{L_{A}} .
$$

Because the substrate is set to be lossless and the metal material is supposed to be perfect electrical conductor, the result of (1) will be the leakage constant $\alpha$ only.

The propagation constant $\beta$ can be calculated indirectly by radiation pattern of the antenna by [16]

$$
\sin \phi_{\mathrm{MB}}=\frac{\beta}{k_{0}},
$$

where $\phi_{\mathrm{MB}}$ is the main beam direction of the antenna, and $k_{0}$ is the wave number in free space. The variations of $\alpha$ and $\beta$ with $W$ are given in Figures 3(a) and 3(b), respectively, and the $H$-plane radiation patterns of the antenna used to calculate $\beta$ are given in Figure 4 . It is found that when $W$ increases, $\alpha$ decreases, but $\beta$ increases. Therefore, when $W$ increases, the power radiated from the opening aperture of the waveguide will also decrease, but the main beam of the antenna will approach to the antenna axis.

\subsection{Relationship between Leakage Factor and Aperture Field} Distribution. For low SLL design, we must find a way to adjust the aperture field distribution; as we know, by changing the aperture depth $W$, the field strength in the aperture can be adjusted. It is difficult to directly establish the relationship between the aperture depth and aperture field distribution. However, the aperture field distribution $E(y)$ and the leakage factor distribution $\alpha(y)$ have the following relationship [16]:

$$
\alpha(y)=\frac{(1 / 2)|E(y)|^{2}}{(1 /(1-R)) \int_{0}^{L_{A}}|E(\zeta)|^{2} d \zeta-\int_{0}^{l}|E(\zeta)|^{2} d \zeta}
$$

where $l$ is the distance from the origin to the considered point in the aperture and $R$ represents the ratio of power absorbed by the terminal load and can be calculated by

$$
R=\left|S_{21}\right|^{2} .
$$

By combining (3) with Figure 3(a), we can indirectly get the relationship between the aperture field and the aperture depth.

In (3), the value of $R$ actually is varying with the aperture field distribution, but if the length of antenna is fixed and the aperture depth changes within a limited range, the variation of $R$ is not significant and can be set to the average of the values under different aperture depths in the considered range. This approximation simplifies the designing procedure significantly. For the antenna structure and parameters used in this paper $\left(L_{A}=136 \mathrm{~mm}\right.$, and $W$ changes from $7.1 \mathrm{~mm}$ to $8.5 \mathrm{~mm}), R$ is set to the average of 0.5 .

\section{Design and Optimization of the Antenna}

3.1. Design of Antenna Structure and Discussion of Results. It is indicated in [11] that if $E(y)$ follows the cosine distribution, the antenna will have low SLL. Thus, in this paper, the aperture field is also designed to be the cosine distribution

$$
E(y)=1.5 \cos \left(\frac{\pi}{136} y-\frac{\pi}{2}\right)+2 .
$$




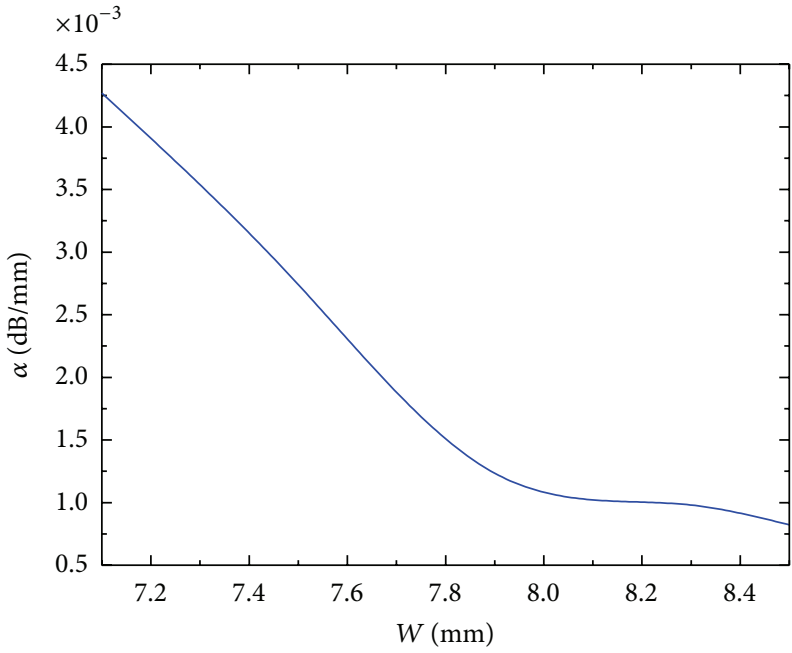

(a) $\alpha$

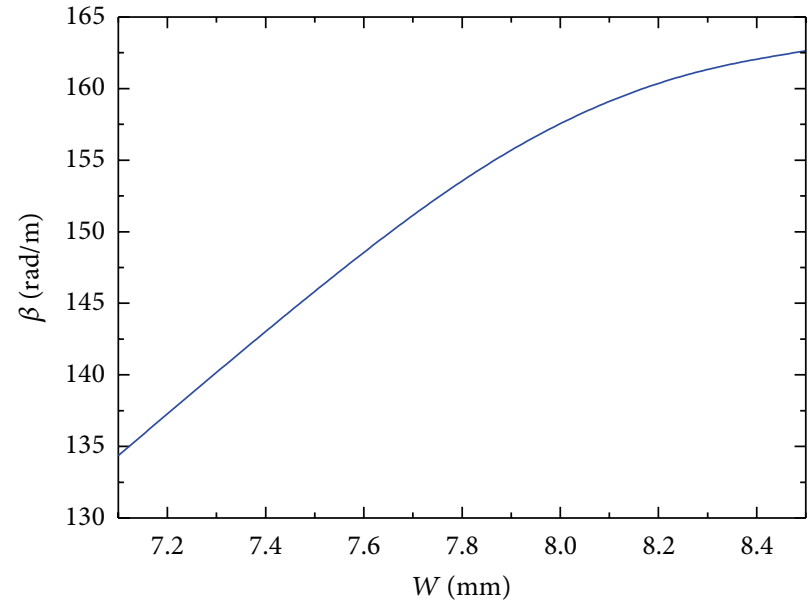

(b) $\beta$

FIGURE 3: Variations of leakage constant and propagation constant as functions of $W$.

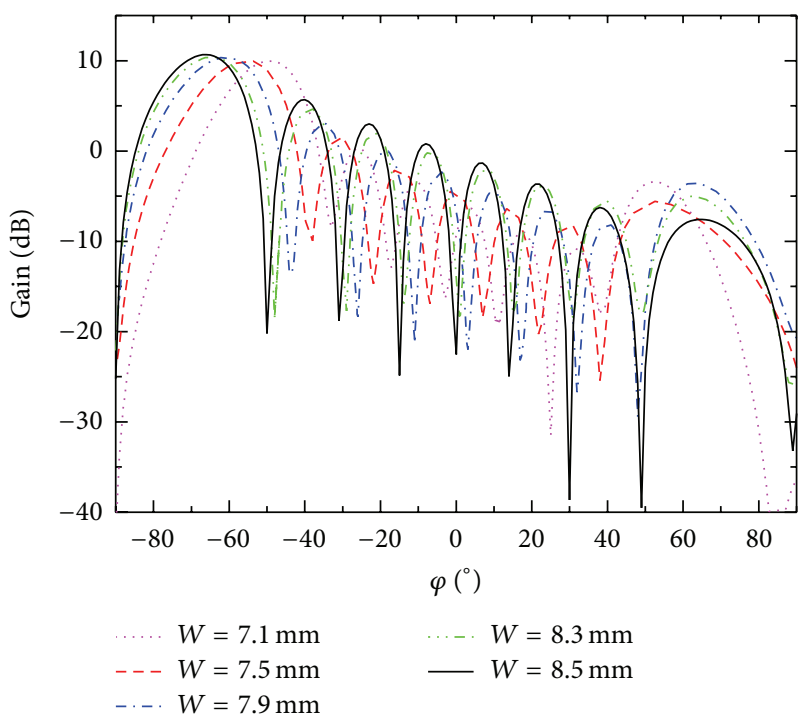

FIgURE 4: Variation of radiation pattern with the aperture depth $W$.

By substituting (5) into (3), the distribution of $\alpha(y)$ can be obtained and is shown in Figure 5. By combining Figure 5 with Figure 3(a), the variation of the aperture depth $W$ along the waveguide can be achieved by one-dimensional linear interpolation method and is shown in Figure 6.

According to Figure 6, the structure of the designed antenna with low SLL can be obtained, as shown in Figure 7. Since the wave power is attenuated when traveling along the HMSIW structure, the distribution of $\alpha$ along the leakage aperture becomes an asymmetrical cosine function; this further leads to the phenomenon that the minimal value of $W$ is not occurring in the center of the aperture.

The simulated radiation pattern in $H$-plane of the cosine distribution tapered LWA is given in Figure 8, comparing with that of the LWA with uniform waveguide with

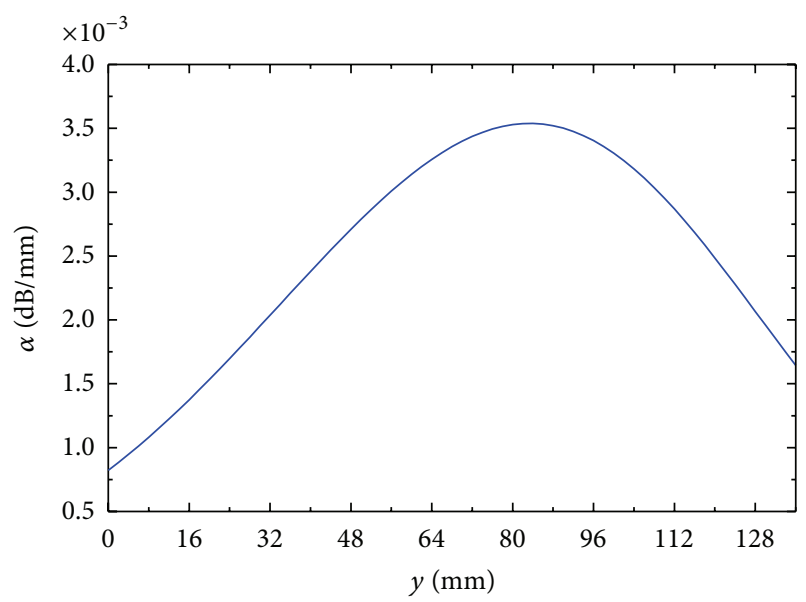

FIGURE 5: Distribution of $\alpha(y)$.

$W=8.5 \mathrm{~mm}$. It can be seen that the SLL of tapered LWA is reduced about $6.8 \mathrm{~dB}$. However, variation of the phase constant $\beta$ with width $W$ makes the main beam width a little bit wider and leads to a shift of beam direction.

3.2. Optimization for Lower SLL. In order to further reduce the SLL of the antenna, the locations of the via hole array are optimized. It is found that when the via holes at other locations are moved closer to the leakage aperture by $0.3 \mathrm{~mm}$, while the via holes at $80 \mathrm{~mm}, 82 \mathrm{~mm}, 84 \mathrm{~mm}$, and $86 \mathrm{~mm}$ are moved by $0.5 \mathrm{~mm}, 0.6 \mathrm{~mm}, 0.6 \mathrm{~mm}$, and $0.5 \mathrm{~mm}$ to the aperture, respectively, as shown in Figure 9, then we can get a relative minimum SLL. The radiation pattern after optimization is shown in Figure 10, and the radiation pattern for the antennas before optimization is also given for comparison. It can be found that the SLL of the optimized LWA is reduced by $2.0 \mathrm{~dB}$ compared with that of the nonoptimized antenna, but the main beam direction and beam width are 


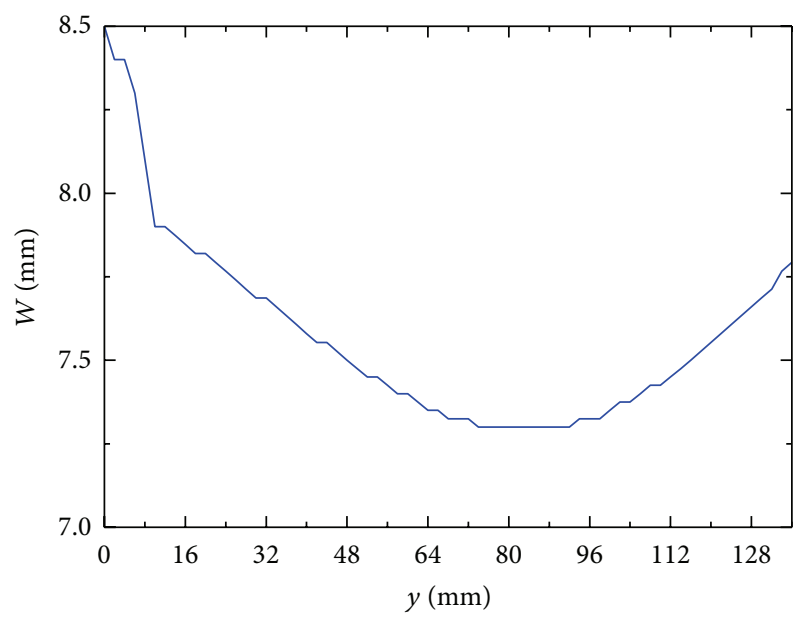

FIgURE 6: Variation of the width $W$ along $y$-axis.

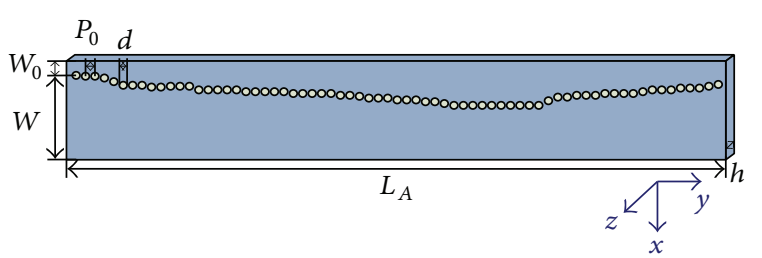

Figure 7: Structure of the designed low SLL HMSIW LWA.

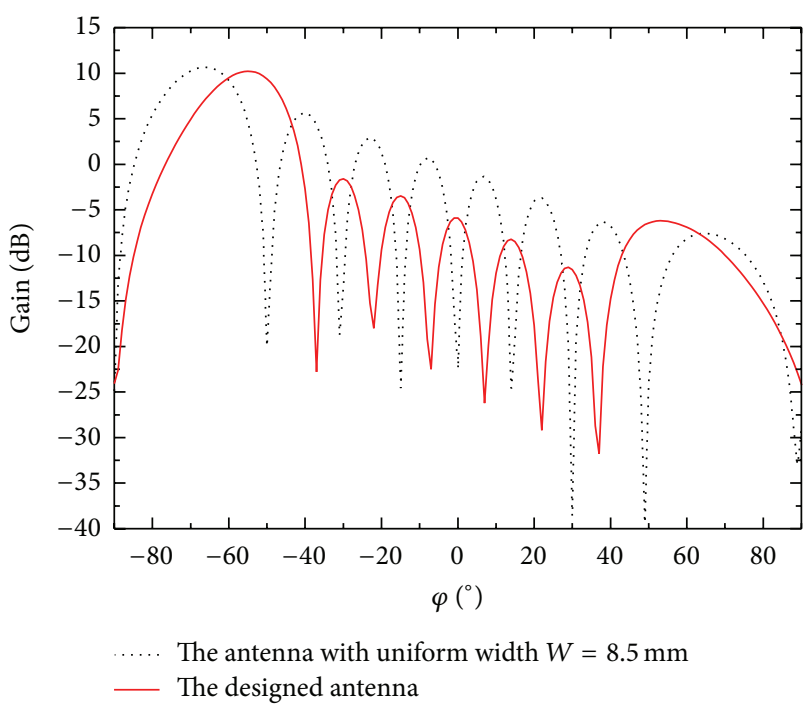

Figure 8: Radiation pattern of the designed antenna.

reduced by $5^{\circ}$ and $1^{\circ}$, respectively, comparing with those of the nonoptimized antenna.

\section{Conclusion}

In this paper, the effects of the structural parameters of the HMSIW LWAs on leakage loss factor $\alpha$ and propagation constant $\beta$ are studied first. Based on the results, the antenna with the characteristic of low SLL is designed and realized by

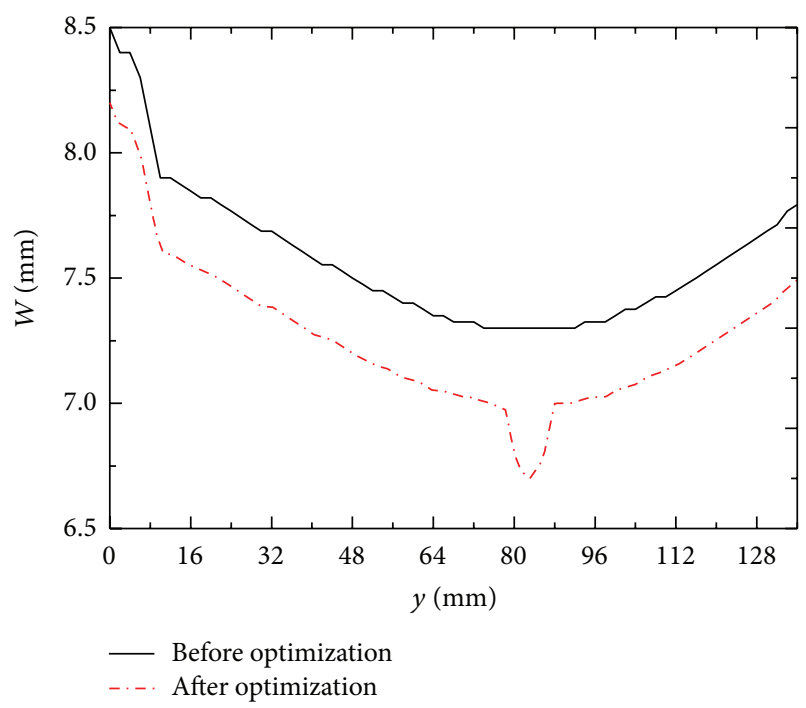

FIgURE 9: Variation of the aperture depth before and after optimization.

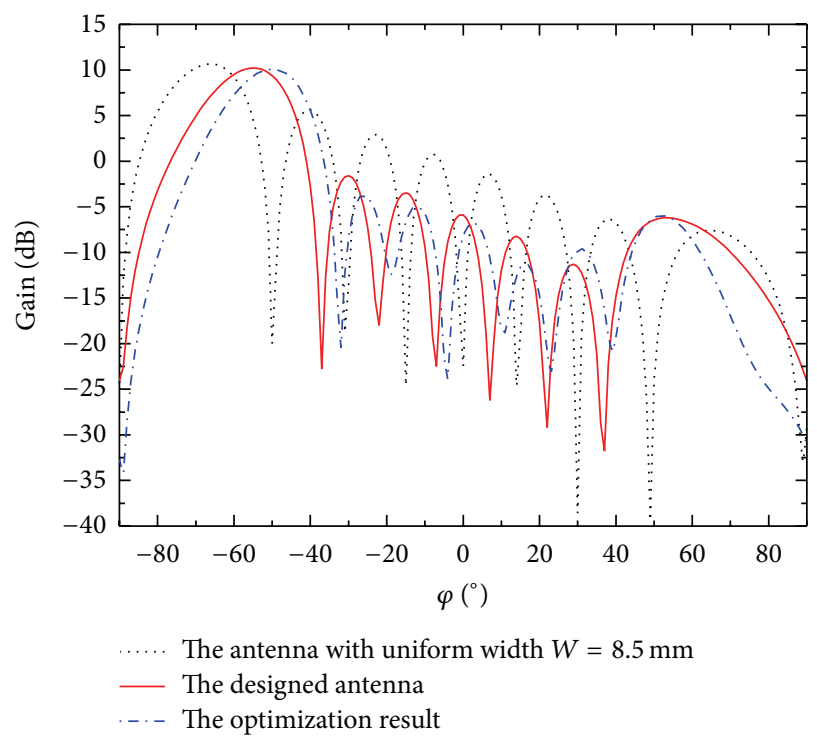

FIGURE 10: Radiation patterns of the designed antenna before and after optimization.

a HMSIW with cosine aperture field distribution. The SLL of the designed antenna is $6.8 \mathrm{~dB}$ lower than that of the antenna with uniform aperture field distribution. Furthermore, an additional decrease of $2.0 \mathrm{~dB}$ can be achieved after optimization of the antenna structure. From the results we can see that the design scheme for reducing the SLL of HMSIM is effective.

\section{Conflict of Interests}

The authors declare that there is no conflict of interests regarding the publication of this paper. 


\section{Acknowledgments}

This work was supported by in part by the National Nature Science Foundation of China under Grant 61331002 and in part by the National Program on Key Basic Research Project (973 Program) under Grant no. 2013CB328903.

\section{References}

[1] W. W. Hansen, "Radiating electromagnetic waveguide," U.S. Patent no. 2,402,622, 1940.

[2] L. O. Goldstone and A. A. Oliner, "Leaky-wave antennas I: rectangular waveguides," IRE Transactions on Antennas and Propagation, vol. 7, no. 4, pp. 307-319, 1959.

[3] L. O. Goldstone and A. A. Oliner, "Leaky wave antennas II: Circular waveguides," IRE Transactions on Antennas and Propagation, vol. 9, no. 3, pp. 280-290, 1961.

[4] J. L. Gómez-Tornero, A. D. L. T. Martínez, D. C. Rebenaque, M. Gugliemi, and A. Álvarez-Melcón, "Design of tapered leaky-wave antennas in hybrid waveguide-planar technology for millimeter waveband applications," IEEE Transactions on Antennas and Propagation, vol. 53, no. 8, pp. 2563-2577, 2005.

[5] D. Deslandes and K. Wu, "Integrated microstrip and rectangular waveguide in planar form," IEEE Microwave and Wireless Components Letters, vol. 11, no. 2, pp. 68-70, 2001.

[6] D. Deslandes and K. Wu, "Substrate integrated waveguide leaky-wave antenna: concept and design considerations," in Proceedings of the Asia-Pacific Microwave Conference (APMC '05), December 2005.

[7] W. Hong, B. Liu, Y. Wang et al., "Half mode substrate integrated waveguide: a new guided wave structure for microwave and millimeter wave application," in Proceedings of the Joint 31st International Conference on Infrared Millimeter Waves and 14th International Conference on Teraherz Electronics (IRMMW-THz '06), p. 219, IEEE, Shanghai, China, September 2006.

[8] J. Xu, W. Hong, H. Tang, Z. Kuai, and K. Wu, "Half-mode substrate integrated waveguide (HMSIW) leaky-wave antenna for millimeter-wave applications," IEEE Antennas and Wireless Propagation Letters, vol. 7, pp. 85-88, 2008.

[9] Y. Cheng, W. Hong, and K. Wu, "Half mode substrate integrated waveguide (HMSIW) directional filter," IEEE Microwave and Wireless Components Letters, vol. 17, no. 7, pp. 504-506, 2007.

[10] W. Hong, B. Liu, G. Q. Luo et al., "Integrated microwave and millimeter wave antennas based on SIW and HMSIW technology," in Proceedings of the International Workshop on Antenna Technology: Small and Smart Antennas Metamaterials and Applications (IWAT '07), pp. 69-72, March 2007.

[11] F. L. Whetten and C. A. Balanis, "Meandering long slot leakywave waveguide-antennas," IEEE Transactions on Antennas and Propagation, vol. 39, no. 11, pp. 1553-1560, 1991.

[12] Y. J. Cheng, W. Hong, K. Wu, and Y. Fan, "Millimeter-wave substrate integrated waveguide long slot leaky-wave antennas and two-dimensional multibeam applications," IEEE Transactions on Antennas and Propagation, vol. 59, no. 1, pp. 40-47, 2011.

[13] A. J. Martinez-Ros, J. L. Gómez-Tornero, and G. Goussetis, "Planar leaky-wave antenna with flexible control of the complex propagation constant," IEEE Transactions on Antennas and Propagation, vol. 60, no. 3, pp. 1625-1630, 2012.

[14] A. J. Martinez-Ros, J. L. Gómez-Tornero, and G. Goussetis, "Flexible pattern synthesis with SIW LWAs," in Proceedings of the European Conference on Antennas and Propagation (EuCAP '12), pp. 229-233, IEEE, March 2012.
[15] A. J. Martinez-Ros, J. L. Gómez-Tornero, and G. Goussetisy, "Independent control of the leakage rate and pointing angle of a novel planar leaky-wave antenna," in Proceedings of the 5th European Conference on Antennas and Propagation (EUCAP '11), pp. 1919-1922, April 2011.

[16] A. A. Oliner and D. R. Jackson, "Leaky-wave antennas," in Antenna Engineering Handbook, J. L. Volakis, Ed., chapter 11, McGraw-Hill, New York, NY, USA, 4th edition, 2007. 

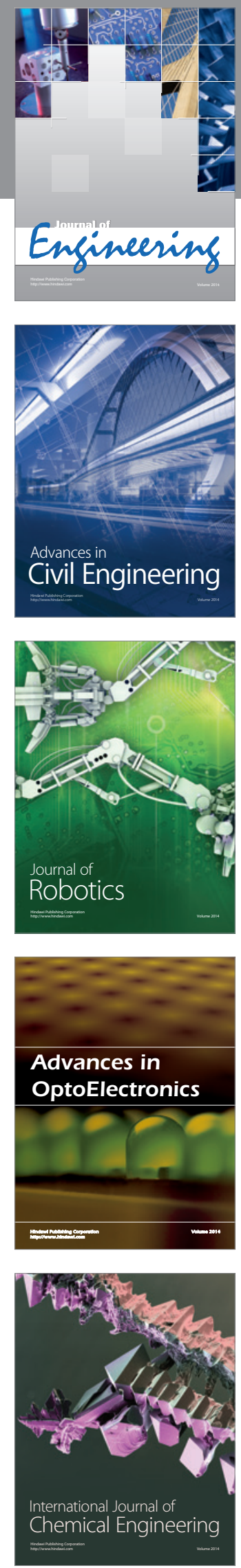

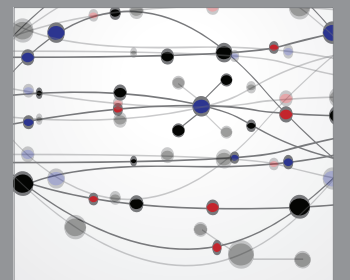

The Scientific World Journal
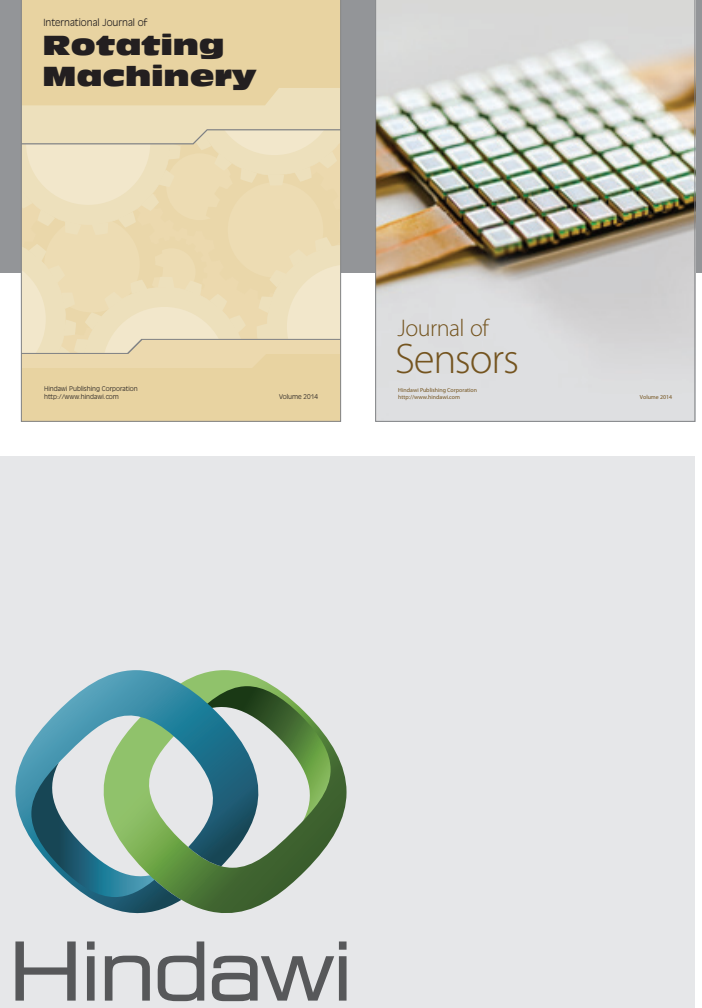

Submit your manuscripts at http://www.hindawi.com
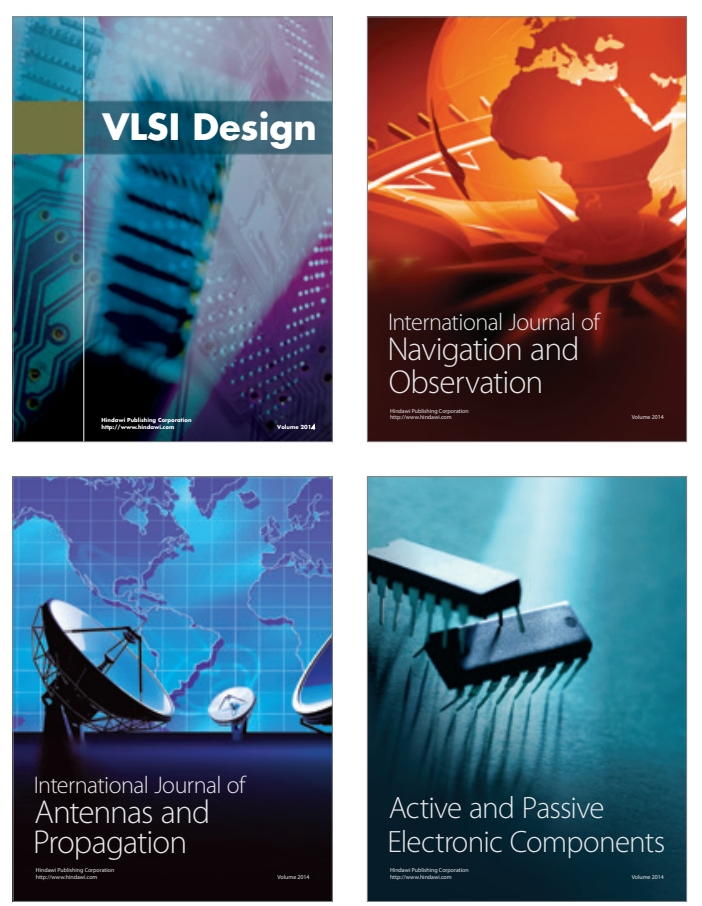
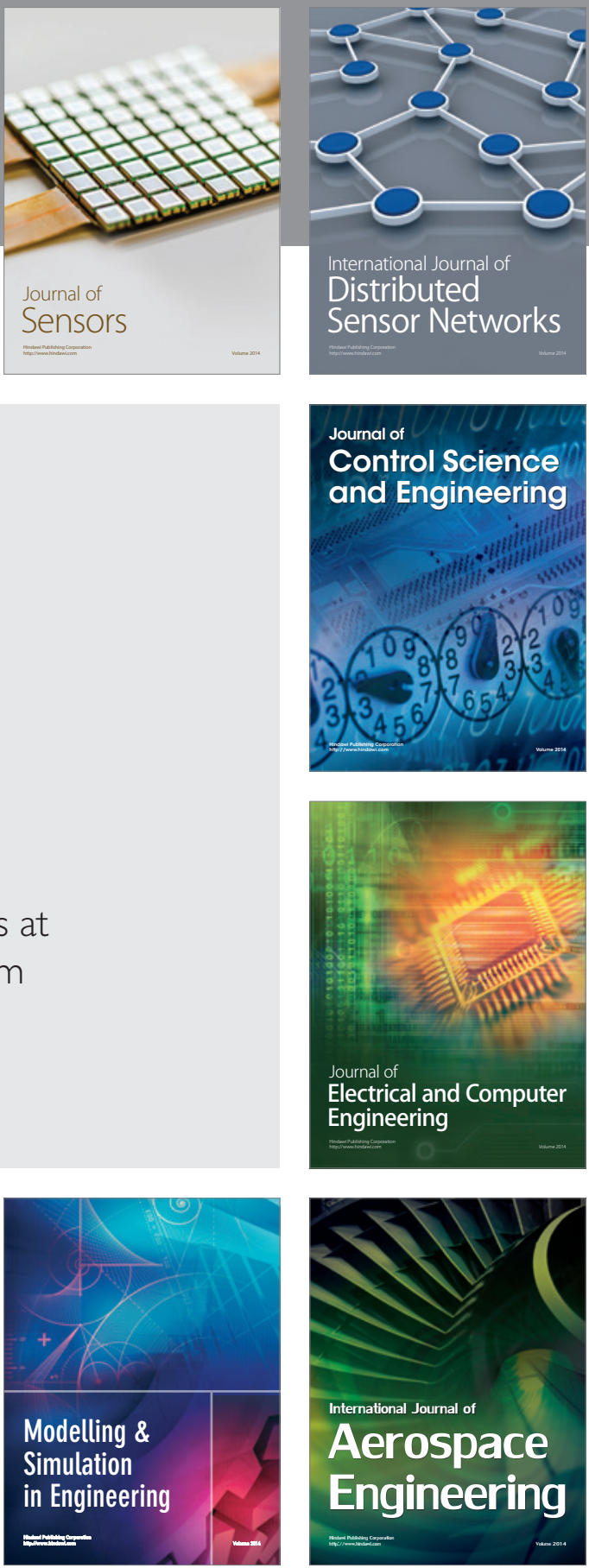

Journal of

Control Science

and Engineering
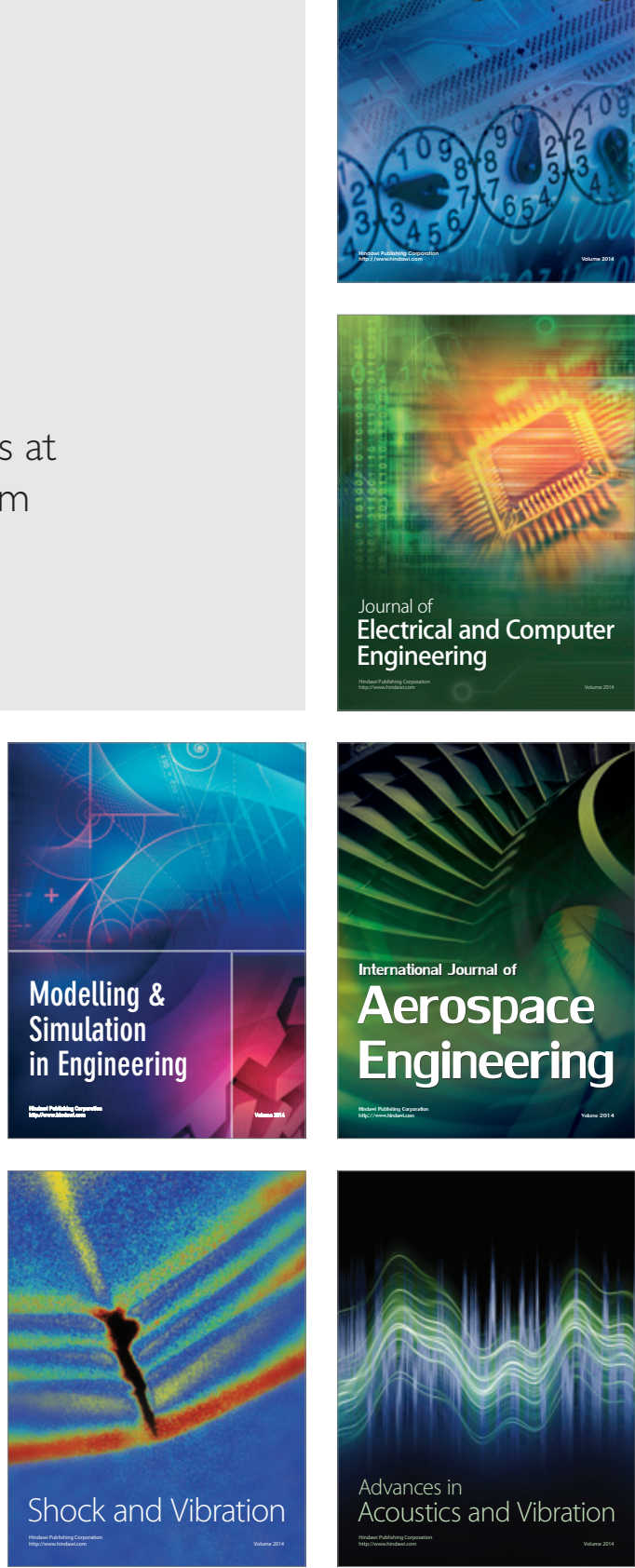